\title{
Immune response to hepatitis $B$ vaccine following complete immunization of children attending two regional hospitals in the Southwest region of Cameroon: a cross sectional study
}

Ephesians N. Anutebeh 1,2, Lambed Tatah ${ }^{2,3}$, Vitalis F. Feteh ${ }^{2,4}$, Desmond Aroke ${ }^{2,5,6}$, Jules C. N. Assob ${ }^{1,6,8}$ and Simeon Pierre Choukem ${ }^{1,2,7^{*}}$

\begin{abstract}
Background: Hepatitis B virus (HBV) infection despite being a vaccine preventable disease remains a global public health problem. In Cameroon, the hepatitis B vaccine was introduced in the expanded program on immunisation in 2005 , but there has been limited evaluation of the HBV surface antibody response post vaccination.

Objective: We investigated the immune response to hepatitis B vaccine in infants who received the DPT-Hep B-Hib vaccine, and we assessed HBsAg carriage in non-responders. We also investigated factors associated with nonresponse or poor response.

Methods: Using a hospital based cross sectional design and a structured questionnaire over a four-month period (January to April 2019), we collected data to determine factors associated with hepatitis B surface antibody (anti-HBs) response from infants aged 6 to 9 months attending infant welfare clinics (IWC) at the Buea and Limbe regional hospitals. We collected venous blood and measured anti-HBs titres using a quantitative Foresight ${ }^{\circledR}$ ELISA. We entered and analysed data using EpiData version 3.1 and SPSS version 25 respectively.
\end{abstract}

Results: Of the 161 infants enrolled, 159 (98.8\%) developed anti-HBs antibodies. Of these 159, 157 (97.5\%) and 117 (72.7\%) developed $\geq 10.0 \mathrm{mIU} / \mathrm{ml}$ (seroprotection) and $\geq 100.0 \mathrm{mlU} / \mathrm{ml}$ anti-HBs titres respectively. Being younger (6 months old) was associated with seroprotection (Cramer $V=0.322, p=0.001$ ). Spearman rho's relational analysis showed that immunity against HBV reduced as the duration since the last dose increased $(r=-0.172 ; P=0.029)$. However, a Firth logistic regression showed no significant association of factors with inadequate immunity. All 12 (7.5\%) infants exposed to HBV at birth, received the hepatitis B vaccine at birth, including four who received HBIG, and all were protected. Four infants (2.5\%) had anti-HBs titres $<10.0 \mathrm{mlU} / \mathrm{mL}$ (non-responders) but had no peculiarity.

Conclusion: The seroprotective rate following hepatitis B vaccination of infants is high even in exposed infants. Our study suggests that Cameroon's HBV vaccine in the Expanded Program on Immunisation (EPI) is effective against HBV,

\footnotetext{
*Correspondence: schoukem@gmail.com

${ }^{7}$ Faculty of Medicine and Pharmaceutical Sciences, University

of Dschang, Dschang, Cameroon

Full list of author information is available at the end of the article
}

(C) The Author(s) 2021. Open Access This article is licensed under a Creative Commons Attribution 4.0 International License, which permits use, sharing, adaptation, distribution and reproduction in any medium or format, as long as you give appropriate credit to the original author(s) and the source, provide a link to the Creative Commons licence, and indicate if changes were made. The images or other third party material in this article are included in the article's Creative Commons licence, unless indicated otherwise in a credit line to the material. If material is not included in the article's Creative Commons licence and your intended use is not permitted by statutory regulation or exceeds the permitted use, you will need to obtain permission directly from the copyright holder. To view a copy of this licence, visit http://creativecommons.org/licenses/by/4.0/. The Creative Commons Public Domain Dedication waiver (http://creativeco mmons.org/publicdomain/zero/1.0/) applies to the data made available in this article, unless otherwise stated in a credit line to the data. 
although we could not account for the $2.5 \%$ non-response rate. Large scale studies are needed to further explore non-response to the vaccine.

Keywords: Hepatitis B vaccine, Immune Response, Infants, EPI, Cameroon

\section{Introduction}

Hepatitis B virus (HBV) is a DNA virus of the Hepadnaviridae family, and it is responsible for both acute/ chronic liver pathology [1]. About a third of the world's population have serologic evidence of current or past HBV infection [2]. Of these, an estimated 257 million are chronic carriers and 887,000 persons die annually due to HBV infection or it's complications [3]. Although HBV has a global spread, the geographical patterns of its prevalence vary hugely. Regions are divided into low, intermediate, and high endemicity. In Sub-Saharan Africa, HBV is highly endemic with a HBsAg prevalence ranging from 5 to $10 \%$ [4], and Cameroon stands out with an estimated prevalence of $11.2 \%$ [5].

In highly endemic areas, HBV in infants is most spread through perinatal transmission. Infection with HBV can be asymptomatic or can cause acute hepatitis. These conditions either resolve spontaneously with subsequent immunity or lead to a chronic infection that is lifelong [6]. About $90 \%$ of infants infected within the first year of life will progress to a chronic disease state. However, the rate of progression to chronic infection decreases with increasing age of primary acquisition $[7$, 8].

Vaccination of infants and neonates against the HBV infection has been found to greatly decrease the burden of the disease [9]. A safe and effective vaccine has been available since 1982, and only started in Cameroon in 2005. The goal is to prevent HBV infection and its complications $[1,7]$. Given the high success with vaccination, the World Health Organisation has recommended the routine screening of pregnant women and implementation of appropriate measures during childbirth to reduce transmission, including the vaccination of every newborn. Testing and vaccination of adults who test negative for HBsAg are also recommended measures to curb the spread of HBV. A course of three doses of hepatitis $B$ vaccine induces protective levels of antibody to HBsAg in over $95 \%$ of healthy infants and children [10, 11]. Antibody titres above $10 \mathrm{mIU} / \mathrm{ml}$ are protective [12, 13]. However, effectiveness of the vaccine is influenced by host factors (age, comorbidity, prior exposure to HBV, and time since vaccination) and vaccine-related factors (type, dose and schedule of vaccine used) [9, 14, 15]. There has been a decrease in the proportion of chronic HBV infection in African children under 5 years of age from $4.7 \%$ in the pre-vaccine era to $1.3 \%$ as of 2015 [3].
Generally, about $5-10 \%$ of vaccinated infants may not develop the expected immune response following complete HBV vaccination [16]. This is due to several factors ranging from site of vaccination to genetic variability of individuals. Studies have shown that the longer the duration between the second and third doses of the vaccine, the higher the immune response [1].

The Expanded Program on Immunisation (EPI) in Cameroon recommends the vaccination of all newborns, and there are continuous vaccination campaigns to ensure good coverage, with generally high uptake rates (99\%) [17]. The EPI uses 6, 10- and 14-weeks schedule with just a month difference between the second and third doses of the vaccine. For exposed newborns, it is recommended that both HBIG and hepatitis B vaccine be administered at birth (seroimmunisation), although HBIG is costly for most mothers. Generally, antibody production post vaccination is 1 month to reach its peak and then gradually starts waning as from 3 months post vaccine. However, no test is done after vaccine completion to identify and measure anti HBs production. This implies that little or no measures are taken to control and confirm the effectiveness of the vaccine or vaccine schedule after administration. In Cameroon, there are few data available on the immune response to hepatitis $B$ vaccine and the vaccine schedule used in the EPI. We aimed to determine the antibody response to hepatitis $B$ vaccine and to evaluate factors associated with no or poor response in two regional hospitals in Cameroon.

\section{Methods}

\section{Study design, setting, and population}

We undertook a cross-sectional study in the Southwest region of Cameroon, where we recruited participants over a period of four months (January to April 2019). Our target population was infants attending Infant Welfare Clinics (IWC) in the Buea Regional Hospital (BRH) and Limbe Regional Hospital (LRH). These hospitals are the major hospitals in the Southwest region of Cameroon, and they each receive averagely $80-100$ infants per month for routine vaccination visits. These facilities have well equipped laboratories with the materials needed for sample collection, adequate storage, and analysis. Even though the LRH has multiple IWC visit days per week and a larger general population compared to $\mathrm{BRH}$, we did not intend to compare results between the two hospitals. 


\section{Sampling method}

All infants aged 6-9 months with documented evidence of receiving all three doses of the HBV vaccine and last dose received at least a month prior to the study were sampled for this study. Infants were met at the various IWC Centres and the study explained to the parents or guardians. Those who consented to participation orally then signed a written consent and were enrolled. We excluded all infants with documented evidence of $\mathrm{HBV}$ infection and further excluded infants with insufficient blood samples.

\section{Sample size estimation}

Our minimum sample size of 114 participants was calculated using the Cochran's formula [18]:

$\boldsymbol{n}=\frac{\boldsymbol{Z}^{2} \boldsymbol{p}(1-\boldsymbol{p})}{\boldsymbol{d}^{2}}$ where $\mathrm{n}=$ minimum sample size, $\mathrm{Z}=$ Standard normal Variation which was set at $1.96(\mathrm{p}$ value: 0.05 and $95 \%$ confidence interval), $p=$ anti-HBs seroprevalence in immunized infants. A study carried out in Dakar (Senegal) and Yaoundé (Cameroon) revealed a prevalence of $92 \%$ [19]. Thus, we assumed a $\mathrm{p}=92 \%=0.92$, and $\mathrm{d}=$ precision at 0.05 at $95 \%$ confidence interval.

\section{Study procedure}

We approached parents at the IWC, gave talks on general infant welfare and about the HBV. Participants with infants between 6 and 9 months were approached, study explained to them, and consent obtained.

\section{Laboratory analysis}

\section{Specimen collection, transportation, and storage}

Following participants enrolment, venous blood samples were collected using a 5-ml syringe into a 4-ml serum separating tube. These samples were then transported within 30 min following collection in a blood transport box to the laboratory where samples were centrifuged, serum extracted and stored at $-20{ }^{\circ} \mathrm{C}$. ELISA kits were stored at $4{ }^{\circ} \mathrm{C}$.

\section{Assessment of Hepatitis B surface antibody (anti-HBs) titres}

Commercial quantitative ELISA Foresight ${ }^{\circledR}$ (ACON Laboratories, Inc., USA) was used to determine the presence of antibodies to HBsAg. Tests were performed according to the kit manufacturer's instructions using sandwich ELISA method Foresight ${ }^{\circledR}$ (ACON Laboratories, Inc., USA).

Reagents and samples were removed and allowed to thaw prior to testing. We then prepared the working wash buffer (Tris- $\mathrm{HCl}$ ). For each micro titre plate used, well A1 was left as blank. Calibrators (Standards obtained from the manufacturer containing varying known concentrations of anti-HBs and negative for HBsAg, HCV, and HIV) preserved in $0.1 \% \operatorname{ProClin}^{\mathrm{TM}} 300$ were added into wells B1 to C2. The colour of wells containing calibrator $1-5$ gradually changed from yellow to Blue. Starting from D2 we added our samples. We added $50 \mu \mathrm{L}$ of conjugate containing purified HBsAg bound to peroxidase to each well. We then mixed gently the plate and incubated at $37{ }^{\circ} \mathrm{C}$ for $30 \mathrm{~min}$. Each well was then washed 5 times with $350 \mu \mathrm{L}$ of working wash buffer and dried. To each well, $50 \mu \mathrm{L}$ of substrate A (citrate phosphate buffer containing hydrogen peroxide) and B (buffer containing tetramethylbenzidine [TMB]) were added and incubated at $37{ }^{\circ} \mathrm{C}$ for $15 \mathrm{~min}$. A blue coloration was noticed in positive wells. The reaction was then stopped by adding $50 \mu \mathrm{l}$ of the stop solution $(0.5 \mathrm{M} \mathrm{H} 2 \mathrm{SO} 4)$ to each well. The positive wells that initially developed blue colour changed to yellow while the negative wells (that were initially colourless) remained colourless. All calibrators, buffer, conjugate, substrates and stop solution were from ACON Laboratories, Inc., USA.

The optical densities of the wells were determined immediately using the spectrophotometer at $450 \mathrm{~nm}-700 \mathrm{~nm}$. The concentration of the standards and their optical densities were used to plot a standard curve from which corresponding concentration of the optical densities of the samples were extrapolated.

In order to identify those with HBsAg carriage, all children who had not developed anti-HBs were screened for HBsAg using Wondfo rapid test (Guangzhou Wonfo Biotech Inc., China).

\section{Additional data \\ Data collection}

A semi-structured interview form was used to obtained sociodemographic data and medical information to assess variables such as vaccination status of infants [number of doses, interval between doses, route of administration, use of birth dose of vaccine and use of hepatitis B immunoglobulin (HBIG)], vaccination timeliness, mother's hepatitis B status prior to parturition and immune status. Infants' medical histories (gestational age, birthweight, and past illnesses) were obtained from past records and current anthropometric parameters were measured and recorded to complete the questionnaire by the investigator.

\section{Data analysis}

Participants were identified using unique codes and data were inputted into a secured computer using participants codes only. These data will be deleted at the end of statistical analysis. Data obtained were entered into EpiData version 3.1 and the database exported to IBM SPSS version 25 software (IBM Corporation, Somers, New York) 
and analysed. The primary study outcome was infants with anti HBs titres $>10.0 \mathrm{IU} / \mu \mathrm{L}$ (seroprotection). Continues variables such as age, gestational age and birthweight were discretized. Participant characteristics were summarised using proportions, frequencies and percentages as well as mean and standard deviation (SD) or median and 25th-75th percentiles as appropriate. Spearman correlation test was performed on all the variables to find out if there was any significant relationship between any two variables. Differences between means of quantitative data were tested using Students' t-test while association between the categorical variables was determined using chi squared $\left(\mathrm{X}^{2}\right)$ or Cramer's V test. A p value $<0.05$ was considered statistically significant. We used a Firth logistic regression model with backward deletion for our multivariate analysis since events in our outcome variable were rare.

\section{Results}

\section{Characteristics of study population}

We enrolled 161 infants in the study. The median and interquartile range (IQR) of age of participants were 7 and 3 months. The modal age was 6 months (49.1\%). Females were more represented (57.8\%), and the majority of our participants enrolled at LRH (65.2\%). Twelve (7.5\%) participants were born to HBV carriers and all 12 received the vaccine at birth, although only 4/12 (33.3\%) of the children born to HBV carrier mothers received the HBIG at birth. The mean ( \pm standard deviation) gestational age at birth was $39( \pm 2)$ weeks and average birthweight was $3.38( \pm 0.59) \mathrm{kg}$. Tables 1 and 2 summarize the sociodemographic and clinical characteristics of our participants respectively.

\section{Vaccination timeliness}

The interval between the first and the second dose of hepatitis $B$ vaccine ranged from 1 to 3 months, with the most frequent interval being 1 month (93.2\%). The interval between the second and third dose also ranged from 1 to 3 months, with the most frequent interval being 1 month (88.8\%). Most of our participants strictly followed the EPI schedule with a 1 month interval between each of the 3 doses (81.4\%: 95\% CI 74.8-86.8). The duration since last dose of vaccine ranged from 1 to 7 months with a median and IQR of 4 and 3 months respectively, and most represented being 3 months (24.8\%) prior to study. Table 3 summarises vaccination timeliness of participants.

\section{Prevalence of adequate immunization}

The anti-HBs antibody titre of participants ranged from 0.0 to $257.7 \mathrm{mIU} / \mathrm{ml}$ with a median (25th, 75th percentile) titre of $197.8(95.9,205.6) \mathrm{mIU} / \mathrm{ml}$. Most participants $117(72.7 \%)$ had a high response. Participants with
Table 1 Sociodemographic characteristics of mothers and infants attending Infant Welfare Clinics in Limbe and Buea, Cameroon

\begin{tabular}{lcc}
\hline Variable & $\begin{array}{l}\text { Number of } \\
\text { participants, } \mathbf{N}^{\mathbf{a}}\end{array}$ & $\begin{array}{l}\text { Percentages } \\
\text { (\%) }\end{array}$ \\
\hline Sex & 93 & 57.8 \\
$\quad$ Female & 79 & 49.1 \\
Age & 9 & 5.6 \\
6 months & 6 & 3.7 \\
7 months & 67 & 41.6 \\
8 months & & \\
9 months & 105 & 65.2 \\
Place of sampling & 56 & 34.8 \\
Limbe & & 11.2 \\
$\quad$ Buea & 18 & 59.0 \\
Informant's level of education & 95 & 29.8 \\
Primary & & \\
Secondary & & \\
$\quad$ University & & 95 \\
Religion & & 5 \\
Christian & 153 & \\
Muslim & 8 & \\
\hline
\end{tabular}

${ }^{\mathrm{a}} \mathrm{N}$, total number of participants (161)

immune response $>10.0 \mathrm{mIU} / \mathrm{ml}$ were considered protected against the HBV infection. Of the 161 participants, 157 had anti-HBs titres $>10.0 \mathrm{mIU} / \mathrm{ml}$ giving a prevalence of $97.5 \%$ (95\% CI 94.1-99.2).

\section{Factors associated with adequate immune response}

Younger age was found to be significantly associated with high levels of anti-HBs. Also, in our study, a relational analysis between duration since last dose of vaccine and anti-HBs titre showed a negative correlation, meaning antibody titres had decreased as duration increased. There was no association between anti-HBs response and timely receipt of vaccine. Table 4 summarises factors that might have influenced the immune response. A Firth logistic regression showed no significant association of exposures with outcome variables; however, the events were very rare $(2 / 161)$.

\section{Discussion}

In this study we have shown that almost all of our participants including exposed infants, have adequate immune response to HBV following 3 doses of vaccination received during the routine EPI. The observation of adequate immune response did not vary by timing of vaccination and non-responders had no peculiar finding. Younger age and duration since last vaccine dose were significantly associated with anti-HBs levels. 
Table 2 Clinical Characteristics of infants attending Infant Welfare Clinics in Limbe and Buea, Cameroon

\begin{tabular}{|c|c|c|}
\hline Variable & $\begin{array}{l}\text { Number of } \\
\text { participants } \\
\text { (total) }\end{array}$ & $\begin{array}{l}\text { Percentages } \\
\text { (\%) }\end{array}$ \\
\hline Mother a chronic HBV ${ }^{\mathrm{a}}$ carrier & $12(161)$ & 7.5 \\
\hline Baby received $\mathrm{HBV}^{\mathrm{a}}$ vaccine at birth & $12(12)$ & 100 \\
\hline Received HBIG ${ }^{b}$ at birth & $4(12)$ & 33.3 \\
\hline Mother is HIV ${ }^{C}$ positive & $6(161)$ & 3.7 \\
\hline \multicolumn{3}{|l|}{ Gestational Age at Birth } \\
\hline Preterm & $12(161)$ & 7.5 \\
\hline Term & $149(161)$ & 92.5 \\
\hline \multicolumn{3}{|l|}{ Birthweight } \\
\hline Low birthweight & $8(161)$ & 5 \\
\hline Normal birthweight & $138(161)$ & 85.7 \\
\hline Macrosomia & $15(161)$ & 9.3 \\
\hline \multicolumn{3}{|l|}{ Documented past illnesses } \\
\hline Neonatal infection & $18(161)$ & 11.2 \\
\hline Malaria & $33(161)$ & 20.5 \\
\hline URTI ${ }^{d}$ & $12(161)$ & 7.5 \\
\hline Febrile gastroenteritis & $4(161)$ & 2.5 \\
\hline Others $^{\mathrm{e}}$ & $5(161)$ & 3.1 \\
\hline \multicolumn{3}{|l|}{ Nutritional Status } \\
\hline \multicolumn{3}{|l|}{ Weight for age assessment: } \\
\hline Adequate & $158(161)$ & 98.1 \\
\hline Underweight & $2(161)$ & 1.2 \\
\hline Overweight & $1(161)$ & 0.7 \\
\hline
\end{tabular}

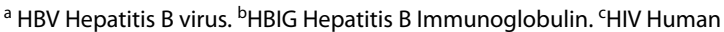
immunodeficiency virus. ${ }^{d}$ URTI Upper respiratory tract infections. ${ }^{e}$ Others (bronchopneumonia, sepsis, urinary tract infections)

We found that most of our participants (97.5\%) mounted adequate immune response following complete vaccination. This finding was in line with the expected global levels of $>95 \%$ [3]. However, a previous study done earlier in Yaoundé Cameroon showed a slightly lower prevalence of 92\% [19]. This observed minor disparity could be explained by the differences in our study population. The earlier study recruited hospitalised patients up to 4 years of age; sick children will have a lower immune response compared to the healthy population as in our study. Moreover, some previous studies from other sub-Saharan African countries such as Senegal, Ethiopia, Ghana and Nigeria, showed lower seroprotection rates of $58 \%, 54 \%, 80.2 \%$, and $61 \%$ respectively [19-22]. The different seroprotection rates could be explained by a number of factors some of which include the different genetic makeup of the individuals involved, the different age groups in the various studies and methodological differences including varied biological assays to measure antibody titres. In addition, the effect of the type of vaccine, dosage of vaccine and storage conditions of the vaccine used could not be ruled out as the above variables were not exploited in other studies. It could therefore be ascertaining that, the hepatitis $B$ vaccine schedule used in the EPI in our setting is highly effective in the prevention of the HBV infection.

The non-response rate which stands at $2.5 \%$ can be compared to those of other developing and developed countries [23-26]. However, the non-response rate in the current study is lower than the anticipated $5-10 \%$ following hepatitis $B$ vaccine immunization in the general population [16, 27]. More so, two out of four of our nonresponders did not seroconvert i.e. had no antibodies detected in their serum, they were both females and had no other peculiarities.

Low birthweight, concurrent chronic disease and immunodepression are the most common reasons for non-attainment of seroprotection amongst vaccinated infants. The low prevalence of these factors in our study population could partly explain the excellent levels of seroprotection observed [28]. Genetic influence and measurement errors could be proposed as probable reason for the non-immune response to HBV immunization among our participants [14]. However, more research is therefore warranted to draw meaningful conclusions.

The mean anti-HBs titre of our participants was protective at $153.5 \mathrm{mIU} / \mathrm{ml}$. There was no significant difference in the mean anti-HBs titres of the males $(153.8 \mathrm{mIU} /$ $\mathrm{ml})$ compared to the mean anti-HBs titre of females $(153.4 \mathrm{mIU} / \mathrm{ml})(\mathrm{p}=0.750)$, which contrast other studies where females responded better to the vaccine than males $[29,30]$ and/or vice versa [21, 31, 32].Younger age was found to be significantly associated with high levels of anti-HBs. Thus, the older children form the majority of those who do not have protective antibody level, and this is consistent with some studies done in sub-Saharan Africa [20, 21] and Europe [33]. More so, in our study, a relational analysis between duration since last dose of vaccine and anti-HBs titre showed a negative correlation, meaning antibody titres had decreased as duration increased. This finding was similar to that of other studies in sub-Saharan Africa [34, 35]. Thus, as children aged the antibody levels produced following vaccination waned.

In our study, three quarters of our participants received the hepatitis vaccines according to the recommended schedule. This timeliness in vaccine administration can also explain the high rate of vaccine response. However, there was no association between anti-HBs response and timely receipt of vaccine. Equally, there was no association between anti-HBs response and those that did not receive the vaccine according to the exact scheduled times. This observation might suggest that children who have defaulted any given dose of the hepatitis vaccine may be encouraged to resume the schedule on the next 
Table 3 Different vaccine schedules followed by infants in Cameroon

\begin{tabular}{|c|c|c|}
\hline Variable & Number of participants $(n=161)$ & $\begin{array}{l}\text { Percentages } \\
\text { (\%) }\end{array}$ \\
\hline \multicolumn{3}{|c|}{ Interval between 1 st and 2 nd dose of $\mathrm{HBV}^{\mathrm{a}}$ vaccine } \\
\hline 1 month & 150 & 93.2 \\
\hline 2 months & 9 & 5.6 \\
\hline 3 months & 2 & 1.2 \\
\hline \multicolumn{3}{|c|}{ Interval between 2nd and 3rd dose of HBV ${ }^{\mathrm{a}}$ vaccine } \\
\hline 1 month & 143 & 88.8 \\
\hline 2 months & 17 & 10.6 \\
\hline 3 months & 1 & 0.6 \\
\hline \multicolumn{3}{|c|}{ Received $\mathrm{HBV}^{\mathrm{a}}$ vaccine on scheduled time according to $\mathrm{EPI}^{\mathrm{b}}$} \\
\hline Yes & 131 & 81.4 \\
\hline No & 30 & 18.6 \\
\hline \multicolumn{3}{|c|}{ Duration since last dose of $\mathrm{HBV}^{\mathrm{a}}$ vaccine } \\
\hline 2 months & 39 & 24.2 \\
\hline 3 months & 40 & 24.8 \\
\hline 4 months & 18 & 11.2 \\
\hline 5 months & 31 & 19.3 \\
\hline 6 months & 29 & 18.0 \\
\hline 7 months & 4 & 2.5 \\
\hline
\end{tabular}

${ }^{a}$ HBV Hepatitis B virus. ${ }^{b}$ EPI Expanded program on immunisation (Interval between vaccine doses 1 month apart)

Table 4 Factors associated with Immune response

\begin{tabular}{|c|c|c|c|}
\hline Factor & All participants $\mathrm{N}^{\mathrm{a}}(\%)$ & Adequate immune response $\mathrm{n}^{\mathrm{b}}(\%)$ & P value \\
\hline Male & $68(42.2)$ & $66(97.1)$ & 0.750 \\
\hline Younger age (6 months) & $79(49.1)$ & $79(100)$ & 0.001 \\
\hline Mother attaining secondary Education & $95(59)$ & $94(98.9)$ & 0.356 \\
\hline Born to Chronic HBV carrier & $12(7.5)$ & $12(100)$ & 0.548 \\
\hline Received HBV ${ }^{c}$ vaccine at Birth & $12(7.5)$ & $12(100)$ & 0.548 \\
\hline Received $\mathrm{HBIG}^{\mathrm{d}}$ at birth & $4(2.5)$ & $4(100)$ & 0.438 \\
\hline Born at term & $149(92.5)$ & $146(98)$ & 0.643 \\
\hline Normal Birthweight & $138(85.7)$ & $134(97.1)$ & 0.710 \\
\hline Neonatal Infection & $18(11.2)$ & $18(100)$ & 0.472 \\
\hline Documented febrile illnesses & $47(29.2)$ & $47(100)$ & 0.193 \\
\hline Mother HIV positive & $6(3.7)$ & $6(100)$ & 0.690 \\
\hline Adequate weight for height for age & $139(86.3)$ & $135(97.1)$ & 0.723 \\
\hline Duration since last vaccine dose $>3$ months & $82(50.9)$ & $80(97.4)$ & $0.029^{f}$ \\
\hline Follows EPI strictly & $131(81.4)$ & $128(97.7)$ & 0.741 \\
\hline
\end{tabular}

Bold values represent statistically significant association of variable with anti-HBs

${ }^{a} \mathrm{~N}$ total number of infants in a particular group. ${ }^{\mathrm{b}} \mathrm{n}$ number of infants with adequate immune response within a particular group. ${ }^{\mathrm{c}} \mathrm{HBV}$ hepatitis b virus. ${ }^{\mathrm{d}} \mathrm{HBIG}$ hepatitis $b$ immunoglobulin. ${ }^{e}$ EPI expanded program on immunization. ${ }^{f}$ Relational analysis between duration since last dosage and anti HBs titre: Spearman's Rho $(R=-0.172 ; P=0.029)$

available opportunity. However, more data are required to clearly elucidate this.

Overall, most of our participants mounted protective levels of anti-HBs titres and followed strictly the EPI schedule. Increasing age and duration since last dose of the vaccine was found to be associated with declining antibody titre levels. The rest of the characteristics of our participants were not significantly associated with the anti-HBs titre levels. No peculiarity of investigated risk factors associated with non-response was also noticed in 
the non-responder population, thus opening windows for questioning of an understudied genetic factor.

\section{Strengths and limitations}

Our study is one of the few studies on immune response to the HBV vaccine in a resource limited setting, Cameroon. Also, our study is the first in a semi urban setting, amongst healthy children and we reached the estimated sample size.

Despite the above findings, our study was limited by its cross-sectional design, thus providing just a onetime snapshot of the immune status of our respondents post vaccination. In addition, our questionnaire required informants to recall information, thus allowing room for recall bias. Also, our data are limited to questions asked in the questionnaire, thus, there are factors that are likely to have an influence on immune response that we could not account for from our collected data.

\section{Conclusion}

We found a high seroprotective rate amongst vaccinated infants in our study; therefore, parents and caregivers should continuously be encouraged to vaccinate their children. Children under one year with a missed dose of HBV should resume the vaccination at the next available opportunity, and vaccine providers should follow the national guidelines to increase vaccine access to all infants. The age and time elapse since last dose of the vaccine inversely correlates with the anti-HBs response. Thus, it is important to establish a nation-wide monitoring process to determine immunity post vaccination. We recommend the need for similar studies to cover larger parts of the country, longitudinal studies to assess the long-term immune response following complete immunisation and further studies to evaluate for HBsAg positivity (i.e., to detect the incidence of HBV infection in infants), given the success of vaccination.

\begin{abstract}
Abbreviations
Anti-HBs: Antibody to hepatitis B surface antigen; BRH: Buea Regional Hospital.; Cl: Confidence interval (95\%); DPT-HepB-Hib: Diphtheria Pertussis Tetanus- Haemophilus influenzae b- hepatitis B; ELISA: Enzyme linked immunosorbent assay.; EPI: Expanded Programme on Immunization; FHS: Faculty of health sciences; HBIG: Hepatitis B immunoglobulins (passive immunization); HBsAg: Hepatitis B surface antigen; HBV: Hepatitis B virus; HCC: Hepatocellular carcinoma; HIV: Human immunodeficiency virus; IWC: Infant Welfare Clinic; LRH: Limbe Regional Hospital; UB: University of Buea; WHO: World Health Organization.
\end{abstract}

\section{Acknowledgements}

We are grateful to all the parents and infants, Directors and staff of the infant welfare clinic unit of the Buea and Limbe Regional Hospital for their immense input to make this work a success. The 2HD (Health and Human Development) research network for their unending guidance.

\section{Authors' contributions}

EA and SC: designed the study, collected and analysed the data, and wrote the manuscript. LT and DA: designed the study, analysed data and wrote the manuscript. JA and VF: analysed data and reviewed the manuscript. All authors read and approved the final manuscript.

\section{Funding}

Not applicable.

\section{Availability of data and materials}

The datasets used and/or analysed during the current study are available from the corresponding author on reasonable request.

\section{Declarations}

Ethics approval and consent to participate

The study was performed in accordance with the ethical standards of the Declaration of Helsinki (1964) and its subsequent amendments. Informed consent was obtained from all the parents and/or legal guardians of the infants included in the study. Ethical approval for this study was obtained from the Institutional Review Board of the Faculty of Health Sciences, University of Buea (IRB-FHS, UB). Administrative approval was obtained from the Regional Delegation of Public Health for the Southwest Region, and the directors of the health institutions included in the study. Confidentiality was ensured throughout the study.

\section{Consent for publication}

Not applicable.

\section{Competing interests}

The authors declare that they have no competing interests.

\section{Author details}

${ }^{1}$ Faculty of Health Sciences, University of Buea, Buea, Cameroon. ${ }^{2}$ Health and Human Development (2HD) Research Network, Douala, Cameroon. ${ }^{3} \mathrm{MRC}$ Epidemiology Unit, University of Cambridge, Cambridge, UK. ${ }^{4}$ Nuffield Department of Medicine, Big Data Institute, University of Oxford, Oxford, UK. ${ }^{5}$ Newark Beth Israel Medical Centre, Newark, NJ, USA. ${ }^{6}$ African Journal of Integrated Health, Buea, Cameroon. ${ }^{7}$ Faculty of Medicine and Pharmaceutical Sciences, University of Dschang, Dschang, Cameroon. ${ }^{8}$ Faculty of Medicine and Pharmaceutical Sciences, University of Douala, Douala, Cameroon.

Received: 9 June 2021 Accepted: 15 November 2021

Published online: 02 December 2021

\section{References}

1. Borrow R, Balmer P, Roper MH. The immunological basis for immunization series Immunization, Vaccines and Biologicals. 2007.

2. Kane MA. Global status of hepatitis B immunisation. Lancet. 1996;348:696.

3. World Health Organization. Global hepatitis report, 2017. Department of HIV/AIDS. Geneva; 2017

4. Taheripour F, Tyner W. Biofuels and land use change: applying recent evidence to model estimates. Appl Sci. 2013;3:14-38.

5. Bigna JJ, Amougou MA, Asangbeh SL, Kenne AM, Noumegni SRN, NgoMalabo ET, et al. Seroprevalence of hepatitis B virus infection in Cameroon: a systematic review and meta-analysis. BMJ Open. 2017;7:1-11.

6. World Health Organisation. Introduction of hepatitis B vaccine into childhood immunization services Management guidelines, including information for health workers and. Department of Vaccines. 2001; CH-1211 Ge.

7. World Health Organisation. Documenting the impact of Hepatitis B immunization: best practices for conducting a serosurvey. 2011; pp. 1-25.

8. McMahon BJ, Alward WL, Hall DB, Heyward WL, Bender TR, Francis DP, Maynard JE. Acute hepatitis B virus infection: relation of age to the clinical expression of disease and subsequent development of the carrier state. J Infect Dis. 1985;151:599-603.

9. WHO. Weekly epidemiological record. 2017;92:369-92. 
10. Schweitzer A, Akmatov MK, Krause G. Hepatitis B vaccination timing: results from demographic health surveys in 47 countries. Bull World Health Organ. 2017;95:199-209G.

11. Inskip HM, Hall AJ, Chotard J, Loik F, Whittle H. Hepatitis b vaccine in the gambian expanded programme on immunization: Factors influencing antibody response. Int J Epidemiol. 1991;20:764-9.

12. Zuckerman JN, Sabin C, Craig FM, Williams A, Zuckerman AJ. Immune response to a new hepatitis $B$ vaccine in healthcare workers who had not responded to standard vaccine: randomised double blind dose-response study. BMJ. 1997;314(7077):329-33.

13. Chathuranga LS, Noordeen F, Abeykoon AMSB. Immune response to hepatitis B vaccine in a group of health care workers in Sri Lanka. Int J Infect Dis. 2013;17:e1078-9.

14. Zuckerman JN. Protective efficacy, immunotherapeutic potential, and safety of hepatitis B vaccines. J Med Virol. 2006;78:169-77.

15. Kruskall MS, Alper CA, Awdeh Z, Yunis EJ, Marcus-Bagley D. The immune response to hepatitis $B$ vaccine in humans: inheritance patterns in families. J Exp Med. 1992;175:495-502.

16. Blumberg EA. MMWR: CDC guidance for evaluating healthcare personnel for hepatitis B virus protection and for administering postexposure management. Am J Transplant. 2014;14:729-31.

17. Bekondi C, Zanchi R, Seck A, Garin B, Giles-Vernick T, Gody JC, et al. HBV immunization and vaccine coverage among hospitalized children in Cameroon, Central African Republic and Senegal: a cross-sectional study. BMC Infect Dis. 2015;15:267.

18. Bartlett J, et al. Sample size in statistics (how to find it) using Cochran'S Formula.Pdf. 2001.

19. Rey-Cuille MA, Seck A, Njouom R, Chartier L, Sow HD, Mamadou BA, et al. Low immune response to hepatitis B vaccine among children in Dakar, Senegal compared to Yaoundé, Cameroon. PLoS ONE. 2012;7:38153.

20. Teshome S. Antibody level against HBV after Hepatitis B vaccination and Sero-prevalence of HBV in children in Addis Ababa, Ethiopia. 2017.

21. Apiung T, Ndanu TA, Mingle JAA, Sagoe KWC. Hepatitis B virus surface antigen and antibody markers in children at a major paediatric hospital after the pentavalent DTP-HBV-Hib vaccination. Ghana Med J. 2017:51:13.

22. Odusanya OO, Alufohai E, Meurice FP, Ahonkhai VI. Human Vaccines Fiveyear post vaccination efficacy of hepatitis B vaccine in rural Nigeria. Hum Vaccin. 2011:625:625-9.

23. Espinoza F, Tregnaghi M, Gentile A, Abarca K, Casellas J, Collard A, et al. Primary and booster vaccination in Latin American children with a DTPwHBV/Hib combination: a randomized controlled trial. 2010.

24. Duval B, Gîlca V, Boulianne N, De Wals P, Massé R, Trudeau G, et al. Comparative long term immunogenicity of two recombinant hepatitis $B$ vaccines and the effect of a booster dose given after five years in a low endemicity country. Pediatr Infect Dis J. 2005;24:213-8.

25. Tregnaghi M, Ussher J, Baudagna AM, Calvari M, Graña G. Comparison of two recombinant hepatitis $B$ vaccines and their interchangeability in Argentine infants Key words. 2004.

26. Basalingappa KM, Kulkarni P. Assessment of immune response and safety of two recombinant hepatitis B vaccines in healthy infants in India. Article in African journal of biotechnology. 2011.

27. CDC Ncird. Hep B-Pink Book. Epidemiology and prevention of vaccinepreventable diseases.149-174. ISSN: 13573039; 2015.

28. Schillie SF, Murphy TV. Seroprotection after recombinant hepatitis B vac cination among newborn infants: a review. Vaccine. 2013;31:2506-16.

29. Moradi A, Khodabakhshi B, Roshandel G, Kalavi K, Besharat S, Semnan S. Response to the hepatitis $B$ virus vaccine in Iranian infants. Hepatitis Monthly. 2009;9:229-31.

30. Zeeshan M, Jabeen K, Ali ANA, Ali AW, Farooqui SZ, Mehraj V, et al. Evalu ation of immune response to Hepatitis $B$ vaccine in health care workers at a tertiary care hospital in Pakistan: an observational prospective study. BMC Infect Dis. 2007:7:120.

31. Salama II, Sami SM, Said ZNA, El-Sayed MH, El Etreby LA, Rabah TM, et al. Effectiveness of hepatitis B virus vaccination program in Egypt: multicenter national project. World J Hepatol. 2015;7:2418-26.

32. El-Sayed, et al. long-term protection of Hep B vaccine amongst Egyptian children. Egypt J Paediatric Allergy Immunol. 2011;9(1):35-40.

33. van Damme P. The journal of infectious diseases long-term protection after hepatitis B vaccine. J Infect Dis. 2016;214:214.

34. van der Sande MAB, Waight PA, Mendy M, Zaman S, Kaye S, Sam O, et al. Long-term protection against HBV chronic carriage of gambian adolescents vaccinated in infancy and immune response in HBV booster trial in adolescence. PLOS ONE. 2007;2:e753.

35. Jack AD, Hall AJ, Maine N, Mendy M, Whittle HC. What level of hepatitis B antibody is protective? J Infect Dis. 1999;179(2):489-92.

\section{Publisher's Note}

Springer Nature remains neutral with regard to jurisdictional claims in published maps and institutional affiliations.
Ready to submit your research? Choose BMC and benefit from:

- fast, convenient online submission

- thorough peer review by experienced researchers in your field

- rapid publication on acceptance

- support for research data, including large and complex data types

- gold Open Access which fosters wider collaboration and increased citations

- maximum visibility for your research: over $100 \mathrm{M}$ website views per year

At BMC, research is always in progress.

Learn more biomedcentral.com/submissions 